\title{
O ensino da anatomia humana através de metodologias ativas de aprendizagem: um relato de experiência
}

\author{
Teaching human anatomy through active learning methodologies: an account of \\ experience
}
Enseñanza de anatomía humana mediante metodologías de aprendizaje activo: un relato de experiencia

Karen Silva de Castro ${ }^{1 *}$, José Benedito dos Santos Batista Neto ${ }^{1}$, Michele Pinheiro Ferreira ${ }^{1}$, Nayara Fernanda Alves Moreira ${ }^{1}$, Livia Caroline ${ }^{1}$ Machado da Silva ${ }^{1}$, Thiago Marcírio Gonçalves de Castro ${ }^{1}$, Lauany Silva de Medeiros ${ }^{1}$, Tania de Sousa Pinheiro Medeiros ${ }^{1}$, Mirian Letícia Carmo Bastos $^{2}$, Natalia Karina Nascimento da Silva².

\section{RESUMO}

Objetivo: Relatar o processo de criação e confecção de uma sequência pedagógica que foi aplicada com a utilização de jogos didáticos para alunos de ensino médio, da rede pública de educação, em um município do Pará. Relato de experiência: A aplicação da dinâmica aconteceu durante uma Feira de Profissão, no dia 18 de maio de 2019. A feira é um evento organizado por todas as universidades de ensino superior para expor os variados cursos de graduação disponíveis aos alunos do ensino médio. Acadêmicos do curso de enfermagem organizaram o "Tabuleiro Anatômico", como forma de chamar a atenção dos alunos para uma conhecida disciplina do curso, Anatomia Humana. A partir disso, a dinâmica aconteceu durante os períodos de manhã, tarde e noite, de $08 \mathrm{~h}$ às $20 \mathrm{~h}$, contando com a participação de cerca de 100 alunos de escolas públicas, estes com idades que variavam de 15 a 20 anos. Considerações finais: A estratégia educativa funcionou como um instrumento no ensino de anatomia, trazendo para uma disciplina tida, como exaustiva a ludicidade, um maior interesse no público infanto-juvenil.

Palavras-chave: Anatomia, Educação em saúde, Aprendizagem, Ludicidade, Jogos.

\begin{abstract}
Objective: To report the process of creating and making a pedagogical sequence that was applied with the use of educational games for high school students, from the public education network, in a municipality in Pará. Experience report: The application of the dynamics happened during a Profession Fair, on May 18, 2019. The fair is an event organized by all universities of higher education to expose the various undergraduate courses available to high school students. Nursing academics organized the "Anatomical Board" as a way to draw students' attention to a well-known course discipline, Human Anatomy. From then on, the dynamics took place during the morning, afternoon and night, from 8 am to $8 \mathrm{pm}$, with the participation of about 100 students from public schools, aged between 15 and 20 years. Final considerations: The educational strategy functioned as an instrument in the teaching of anatomy, bringing to a discipline considered, as playfulness as exhaustive, a greater interest in the children and youth public.
\end{abstract}

Keywords: Anatomy, Health education, Learning, Playfulness, Games.

1 Universidade do Estado do Pará (UEPA), Tucuruí - PA. *E-mail: silvakaren2021@gmail.com

2 Universidade Federal do Pará (UFPA), Belém - PA. 


\section{RESUMEN}

Objetivo: Informar el proceso de creación y realización de una secuencia pedagógica que se aplicó con el uso de juegos educativos para estudiantes de secundaria, de la red de educación pública, en un municipio de Pará. Informe de experiencia: La aplicación de la dinámica sucedió durante a Feria de Profesiones, el 18 de mayo de 2019. La feria es un evento organizado por todas las universidades de educación superior para exponer los diversos cursos de pregrado disponibles para estudiantes de secundaria. Los académicos de enfermería organizaron la "Junta Anatómica" como una forma de llamar la atención de los estudiantes sobre una disciplina de curso muy conocida, Anatomía Humana. A partir de entonces, la dinámica se desarrolló durante la mañana, tarde y noche, de 8 a 20 horas, con la participación de cerca de 100 alumnos de escuelas públicas, con edades comprendidas entre los 15 y los 20 años. Consideraciones finales: La estrategia educativa funcionó como un instrumento en la enseñanza de la anatomía, llevando a una disciplina considerada, tan lúdica como exhaustiva, un mayor interés por el público infantil y juvenil.

Palabras clave: Anatomía, Educación para la salud, Aprendizaje, Alegría, Juegos.

\section{INTRODUÇÃO}

O ensino da Anatomia Humana, tradicionalmente, é abordado com valorização da transmissão e memorização das morfologias e fisiologias dos órgãos que compõem os sistemas orgânicos. Embora os alunos se sintam atraído pela temática, devido ao fato de estar estudando o próprio corpo, a linguagem técnica e complexa torna os conteúdos de difícil entendimento e, consequentemente, prejudicando 0 processo de ensino-aprendizagem (FORNAZIERO AM, 2019).

Dessa forma, é necessária a busca de métodos que amparem estas complexidades, para que haja a disseminação do conhecimento de modo prazeroso, despertando a curiosidade do educando. Essa nova realidade, leva os professores, estudantes de licenciatura e pesquisadores da educação a buscarem alternativas dinâmicas, lúdicas, participativas e autônomas, que envolvam e atraiam o aluno para essa disciplina, favorecendo a relação do conteúdo com o discente (SILVA RA e GUIMARÃES MM, 2018). Além disso, é observado que a educação formal possui um caráter sistemático e, na maioria das vezes, não proporciona o conhecimento de forma interessante e sim como algo imposto, tornando o aprendizado mais difícil, abstrato e fácil de ser esquecido.

Portanto, vários problemas associados ao ensino de Ciências, neste caso de Anatomia Humana, no geral, já foram apontados, onde se pode destacar a falta de trabalhos práticos, por exemplo, no qual o aprendiz seja o protagonista da sua aprendizagem, devendo ser um sujeito ativo na construção do conhecimento. Nesse contexto, ao invés de continuar a decorar conteúdos, o aluno passa a exercitar habilidades e, por meio delas, pode construir novos conteúdos (CALDEIRA AMDA, 2009).

A partir disso, as metodologias ativas de ensino são ferramentas que ampliam e facilitam o ambiente para o processo de ensino-aprendizagem. Isso se dá pelo motivo de possuir uma abordagem crítica e reflexiva, que busca o estímulo no processo de ensino e aprendizagem, fazendo o aluno se envolver cada vez mais na busca pelo conhecimento, tornando-o protagonista do processo, estimulando a autonomia, desenvolvimento da consciência social, ética e técnica, assim como, incentivam o estudante a intervir em problemas reais do dia-a-dia, tendo por objetivo principal deslocar a responsabilidade pelo processo de aprendizagem do professor para o aluno (BERBEL NAN, 2011; MACEDO KDS, et al., 2018).

Logo, o uso de métodos inovadores de ensino se fundamenta em estratégias articuladas em concepções pedagógicas críticas e reflexivas, na qual a intervenção e interpretação sobre a atualidade geram a socialização entre os indivíduos e valoriza novos saberes. Dentre essas metodologias ativas, temos a Aprendizagem Baseada em Jogos, a qual faz uso dos jogos para desenvolver habilidades como memória, atenção e raciocínio, para o processo de educação ativa, pois a sua utilização deixou de fazer parte apenas do lazer e hoje são considerados importantes ferramentas para o repasse de conteúdos conceituais (ROCHA HM e LEMOS WM, 2014). 
Ademais, o uso desse tipo de metodologia de ensino tem como praticidade fazer com que os alunos gostem e se divirtam no aprendizado, uma vez que a transformação da rotina é fundamental para despertar o interesse e a participação do aluno envolvido. Sendo assim, a aprendizagem através de jogos, é um ponto positivo na construção do interesse em aprender. Dessa forma, utilizar do jogo dentro das instituições educacionais é uma alternativa de tornar o processo de ensino criativo, autônomo e consciente (FRIEDMAN A, 1996; NUNES CC, 2017).

Nesse sentido, o objetivo deste trabalho é relatar o processo de criação de uma sequência pedagógica que foi aplicada com a utilização de jogos didáticos, como estratégia facilitadora do ensino e aprendizagem da AH para alunos de ensino médio, da rede pública de educação, em um município no interior do estado do Pará.

\section{RELATO DE EXPERIÊNCIA}

Trata-se de um estudo descritivo, do tipo relato de experiência acerca da criação e utilização de uma sequência pedagógica, fundamentada em metodologias ativas de aprendizagem, como forma de estratégia de ensino de Anatomia Humana para estudantes do ensino médio. A criação e utilização foram realizadas por acadêmicos do $3^{\circ}$ semestre do curso de Enfermagem de uma universidade do interior do estado do Pará.

A aplicação da dinâmica aconteceu durante uma Feira de Profissões, no dia 18 de maio de 2019. A feira é um evento organizado por todas as instituições de ensino superior do município. Nesse contexto, possui como escopo a exposição dos variados cursos de graduação disponíveis na cidade para a visualização de alunos do ensino médio, sendo está uma tentativa de fazer com que estes se sintam estimulados a adentrar na vida acadêmica.

Os acadêmicos do curso de enfermagem organizaram a dinâmica, como forma de chamar a atenção dos alunos para uma conhecida disciplina do curso, Anatomia Humana. Desse modo, a dinâmica aconteceu durante os períodos da manhã, tarde e noite, de $08 \mathrm{~h}$ às $20 \mathrm{~h}$, contando com a participação de cerca de 100 alunos de escolas públicas, estes com idades que variavam de 15 a 20 anos.

Primeiramente, ocorreu a elaboração da proposta pedagógica, por meio, de discussões dentro de sala de aula que ocorreram entre professor-discente e discente-discente, sobre os desafios e estratégias para divulgação da disciplina, como forma de incentivar os alunos a optarem pelo curso de Enfermagem, ensinando através da produção de recursos didáticos, ou seja, por meio, da produção de jogos, maquetes, teatro, música, etc., desde que fosse descritível e reproduzível.

Em seguida, os discentes foram divididos em grupos, em que cada grupo ficaria com um tema específico para a produção do material. Sendo assim, ficou decidido que os assuntos tratados seriam: Anatomia dos Sistemas Digestivo e Sensorial, além do mais, os alunos tiveram um período de 20 dias para pesquisa e preparação dos recursos didáticos para apresentação, evidenciado que os discentes foram instigados a usar a criatividade no desenvolvimento das metodologias ativas.

Logo após, ficou de acordo que iria ser trabalhado os assuntos da seguinte forma: seria explanado um pouco do conteúdo, de forma didática, simples e sempre incentivando a participação dos alunos e, em seguida, os mesmos participariam de um jogo de perguntas e respostas, com premiação, para incentivar sua memória e enumerar a quantidade de acertos e erros no decorrer da atividade.

A partir disso, para realização das atividades propostas e para que estas chamassem a atenção dos indivíduos presentes na feira, os discentes optaram por construir por construir uma estratégia baseada na metodologia ativa da Aprendizagem Baseada em Jogos. Assim sendo, o jogo desenvolvido foi baseado nos elementos básicos dispostos no estudo de Santos AMG et al. (2019), os quais são: atrair visualmente e instigar os jogadores; permitir o jogador se desconstruir, avaliar, perceber o erro e com isso possa melhorar, fixando o aprendizado; e ser dinâmico e ativo, fazendo com que os jogadores participem e estejam sempre em ação durante o jogo. 
Nesse sentido, foi realizada a construção do material, onde foram utilizadas peças anatômicas, sendo uma representação interna e externa de uma orelha humana (Figura 1) fabricado em material sintético que continha as seguintes dimensões: $55 \mathrm{~cm}$ de comprimento, $47 \mathrm{~cm}$ de largura, $59 \mathrm{~cm}$ de comprimento, pesando $3 \mathrm{Kg}$. Também detínhamos da representação de um sistema digestório completo (Figura 2) feito em material sintético, com comprimento, largura e espessura de $90 \mathrm{~cm} \times 32 \mathrm{~cm} \times 14 \mathrm{~cm}$ e 2,2 $\mathrm{Kg}$, disponibilizadas pelo laboratório de anatomia da instituição de ensino ao qual os discentes estudam, para explicar os sistemas mencionados. Ademais, foram confeccionados cartazes informativos e ilustrativos, em cartolinas e papel quarenta quilos, para ajudar na compreensão dos indivíduos sobre a temática abordada.

Figura 1 - Ilustração representativa das peças anatômicas referentes ao sistema sensitivo.

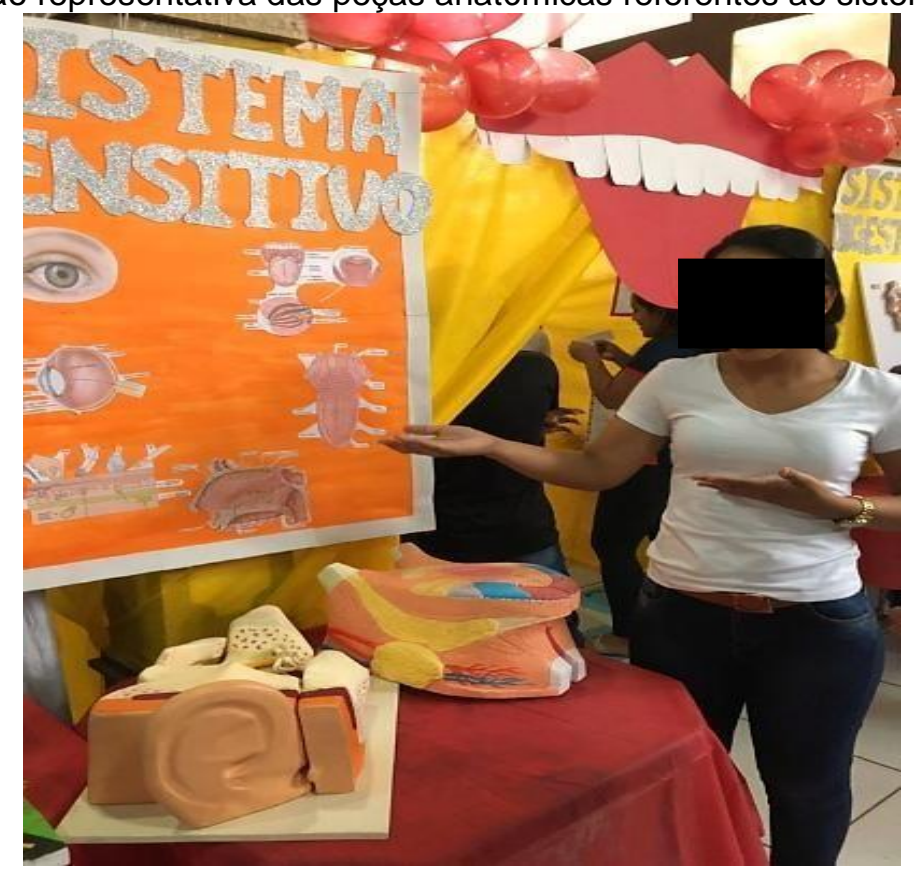

Fonte: Castro KS, et al., 2020.

Figura 2 - llustração representativa das peças anatômicas referentes ao sistema digestório.

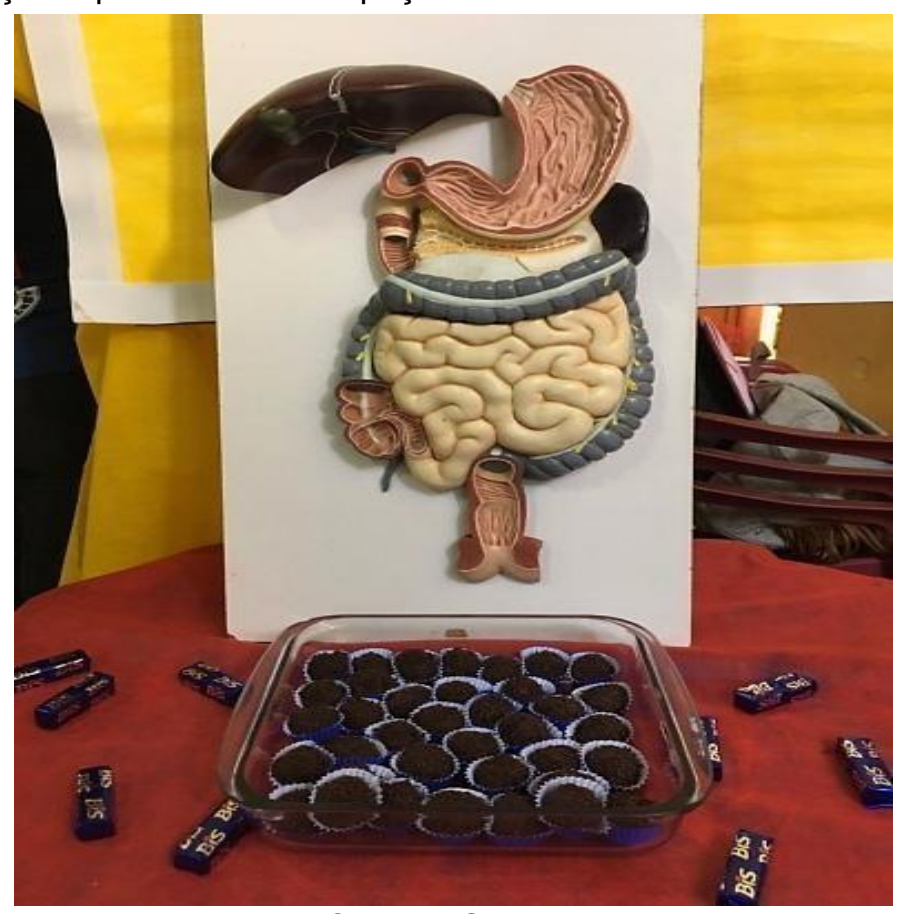

Fonte: Castro KS, et al., 2020. 
Além disso, foi montado uma barraca com cores chamativas, na qual, do lado externo eram realizadas apresentações acerca dos sistemas fisiológicos sensitivo e digestório, que eram mediadas por discentes de enfermagem que utilizavam de peças anatômicas para melhor exemplificarem suas falas. É interessante relatar que os alunos do ensino médio ao verem as peças realistas, sentiam-se interessados, uma vez que podiam manuseá-las e verificar seu funcionamento.

Com essa primeira apresentação finalizada, os alunos eram convidados a adentrar na barraca, a qual possuía em suas paredes, cartazes que continham informações, curiosidades e fotos acerca dos sistemas fisiológicos sensitivo e digestório. Ademais, no centro da barraca, estava localizada a dinâmica em si, o jogo do "Tabuleiro Anatômico", no qual podiam participar 4 pessoas, jogando em duplas, ao mesmo tempo.

O funcionamento jogo acontecia da seguinte maneira: existiam 6 níveis, que eram caracterizados por um quadrado de aproximadamente um metro, sendo que em cada um existia uma pergunta. As duplas funcionavam como pinos de jogos de tabuleiros, sendo assim, à medida que acertavam uma pergunta (Quadro 1), subiam de nível até chegarem ao final. Inicialmente, era sorteado qual dupla jogaria primeiro. $O$ jogo iniciava-se com o coordenador da dinâmica (discente de enfermagem) dando uma caixa fechada com inúmeras perguntas aos iniciantes, que eram sorteadas aleatoriamente e que deveriam ser respondidas, caso errassem passavam a vez para os outros e assim sucessivamente até que alguém chegasse ao final. A dupla vencedora era premiada e assim terminava a dinâmica.

Quadro 1 - Perguntas aplicadas no tabuleiro.

\begin{tabular}{|c|c|}
\hline Sistema Digestório & Sistema Sensitivo \\
\hline $\begin{array}{c}\text { Quais são os órgãos que participam no sistema } \\
\text { digestório? }\end{array}$ & Qual é a função dos sentidos? \\
\hline $\begin{array}{c}\text { Onde ocorre a primeira digestão dos } \\
\text { carboidratos? }\end{array}$ & Onde estão os receptores sensoriais da visão? \\
\hline $\begin{array}{c}\text { O que é a amilase salivar? } \\
\text { que } \quad \begin{array}{c}\text { região está localizado } \\
\text { estômago? }\end{array}\end{array}$ & Qual é o sentido relacionado com os sabores \\
dos alimentos?
\end{tabular}

Fonte: Castro KS, et al., 2020.

\section{DISCUSSÃO}

O estudo da Anatomia Humana não é algo atual, existindo desde séculos passados. É certo que, desde sempre, é uma ciência que desperta interesse em alunos, haja vista que se está aprendendo sobre si mesmo. Entretanto, é inquestionável que também desperta receio, dado que possui peculiaridades de aprendizagem, como por exemplo, adquirir um novo vocabulário, memorizar nomenclaturas, tais ações, com o tempo, tornam-se maçantes para os alunos, fazendo com que possuam um rendimento aquém do esperado (FOUREAUX G, et al., 2018). 
Por conseguinte, como forma de superar os impasses do ensino e aprendizagem dessa disciplina, é necessário que o educador dedique parte de seu tempo para planejar ações didáticas. Assim sendo, durante o processo de ensino, é fundamental que o professor estimule a troca de experiências, o diálogo, a troca de ideias entre todos, o desenvolvimento do senso crítico, portanto, temos que o docente deve utilizar de métodos ativos de ensino, que coloquem o aluno como agente formador de seu próprio conhecimento (FREIRE LI e FERNADEZ C, 2015).

Dentre as principais metodologias utilizadas hoje em dia, temos aquelas que dispõe da ludicidade. É inquestionável que utilizar do lúdico no processo de ensinar desperta um maior interesse no aluno, tornando a experiência de aprender mais agradável, contribuindo para a impregnação do conhecimento e aprendizado (ROMAN C, et al., 2017; COSTA TRM, et al., 2020).

Para mais, seguindo estes preceitos, anteriormente citados, durante o processo de criação da sequência pedagógica, aqui relata, para o ensino da Anatomia Humana, optou-se por utilizar da Aprendizagem Baseada em Jogos, uma vez que, configura-se como sendo uma viável e eficiente metodologia ativa, que utiliza do lúdico para facilitar o ensino-aprendizagem de conteúdos escolares. Sabemos que os jogos permitem que o aluno interaja com o meio, contraindo de forma coletiva conceitos e conhecimentos (SENA S, et al., 2016).

Um dos principais desafios encontrados hoje pelos professores de Anatomia é em relação à definição de quais estruturas ou sistemas mais importantes para serem aprendidas pelos estudantes, que poderão de fato contribuir para sua formação profissional e também sobre a escolha de atividades práticas que possam cativar a atenção do aluno na hora do ensino (COLARES MAM, et al., 2019). Afim de trazer formas alternativas para ensino e apresentação da disciplina e para apresentar o curso de enfermagem para os alunos do ensino médio, utilizou-se a metodologia em questão para uma contribuição mais prazerosa e lúdica como proposta inovadora para o ensino.

A utilização das tecnologias interativas no ensino da anatomia humana, foi de muita relevância para o aprendizado e interesse ao decorrer da exposição, permitindo que os participantes fossem protagonistas no processo de aprendizagem ativa, visto que aplicação desses materiais pode ser adaptados à todas as faixas etárias para promover uma aprendizagem de forma divertida, além da solução de dúvidas e de introspecção em participar das atividades.

Assim, a estratégia educativa elaborada funcionou como um excelente instrumento para o ensino de anatomia, uma vez que conseguiu trazer para uma disciplina, vista como exaustiva, a ludicidade, despertando, portanto, maior interesse no jovem, que estão próximos de adentrar em cursos de nível superior. Ainda, a oferta de um ambiente descontraído, por parte dos preceptores, garantiu que os alunos, ao final da experiência, expressassem suas opiniões acerca do que lhes foi repassado, bem como, favoreceu com que estes se interessassem em buscar cada vez mais conhecimentos (MESQUITA AL, et al., 2016; COSTA TRM, et al., 2020).

No mais, em relação ao desenvolvimento do jogo do tabuleiro, temos que os alunos se comportaram de forma positiva, participaram dando opiniões, dialogando e discutindo entre si para chegarem juntos a conclusões. Felizmente, podemos dizer que tais fatos são características positivas da utilização de metodologias ativas, as quais segundo Barbosa EF e Moura DG (2013), possuem como principal característica permitir que o educando interaja com o objeto em estudo, de forma que ele discuta, ouça, faça, fale, ensine, pergunte, enfim, se torne agente ativo de seu aprendizado.

Neste sentido, a utilização de metodologias ativas e inovadoras no ensino da anatomia, como o jogo, faz com que o participante coloque em prática a capacidade de concentração e raciocínio integrado ao conhecimento corporal de si, dado que eram perguntas relacionadas à anatomia humana, sendo assim, deveriam refletir sobre si mesmos para que encontrassem a solução (OLIVEIRA RR e ABREU MFAA, 2013).

Para mais, outro ponto positivo da realização da dinâmica, característica da Aprendizagem Baseada em Jogos, é o desenvolvimento da socialização, por meio do trabalho em equipe, que era necessário entre os 
alunos para que chegassem a uma resposta. O trabalho em equipe dentro dessas práticas é fundamental, pois ajuda o indivíduo a aprender a lidar com particularidades e pensamentos de terceiros, adquirindo condutas afetivas, sendo que estas contribuem para o desenvolvimento confiança, autonomia e iniciativa (FERNANDES NA, 2010).

Por fim, de uma maneira geral, a utilização de metodologias ativas, com apoio da ludicidade, para o ensino da Anatomia Humana tornou o processo de ensino e aprendizado mais fácil e divertido alunos. A proposta em questão, permitiu que os alunos desenvolvessem o trabalho em equipe, uma vez que dialogaram, opinaram e pensaram juntos. No mais, podemos dizer que estes educandos foram capazes de perceberem o quão importante é participar do próprio processo de ensino, verificando que a assimilação do conteúdo se dá de forma mais facilitada.

\section{AGRADECIMENTOS}

O presente trabalho foi realizado com o apoio do corpo docente da Universidade do Estado do Pará UEPA (Campus XVIII/Tucuruí-PA). Agradecemos ainda a equipe de educadores e corpo discente das instituições de ensino médio envolvidas.

\section{REFERÊNCIAS}

1. BERBEL NAN. As metodologias ativas e a promoção da autonomia de estudantes. Semina Ciências Sociais e Humanas, 2011; 32(1): 25-40.

2. BARBOSA EF, MOURA DG. Metodologias ativas de aprendizagem na educação profissional e tecnológica. Boletim Técnico do Senac, 2013; 39(2): 48-67.

3. CALDEIRA AMDA. Ensino de ciências e matemática II: temas sobre a formação de conceitos. São Paulo: UNESP, 2009; 287p.

4. COLARES MAM, et al. Metodologias de ensino de anatomia humana: estratégias para diminuir as dificuldades e proporcionar um melhor processo de ensino-aprendizagem. Arquivos do MUDI, 2019; 23(3): 140 - 160.

5. COSTA TRM, et al. Aplicação do lúdico para o ensino de saúde na educação médica da cidade de Parnaíba, Piauí: relato de experiência. Revista Eletrônica Acervo Saúde, 2020; 12(11): e3833.

6. FERNANDES NA. O uso dos jogos educacionais no processo de ensino e aprendizagem. Monografia (Especialização em Mídias na Educação) - Centro Interdisciplinar de Novas Tecnologias na Educação. Universidade Federal do Rio Grande do Sul, 2010; 62p.

7. FORNAZIERO AM. Efeitos de um jogo de futebol sobre marcadores fisiológicos, bioquímicos e de performance. Universidade Federal do Paraná. Faculdade de Educação. Curitiba: DSPACE, 2019; 124p.

8. FOUREAUX G, et al. O ensino-aprendizagem da anatomia humana: avaliação do desempenho dos alunos após a utilização de mapas conceituais como uma estratégia pedagógica. Revista Ciências \& Educação, 2018; 24(1): 95 110.

9. FREIRE LIF, FERNANDEZ C. O professor universitário novato: tensões, dilemas e aprendizados no início da carreira docente. Revista Ciência \& Educação, 2015; 21(1): 255-272.

10. FRIEDMAN A. Brincar, crescer e aprender: O resgate do jogo infantil. São Paulo: Moderna, 1996; $5 p$.

11. MACEDO KDS, et al. Metodologias ativas de aprendizagem: caminhos possíveis para a inovação no ensino em saúde. Esc Anna Nery, 2018; 22(3): e20170435.

12. MESQUITA AL, et al. Metodologias lúdicas aplicadas ao curso de medicina. Revista Educação em Saúde, 2016; 3(suplemento 2): $44 \mathrm{p}$.

13. NUNES CC. A utilização de jogos pedagógicos como ferramenta facilitadora na aprendizagem de aspectos gramaticais de língua estrangeira: uma estratégia ludopedagógica. Revista do Curso de Letras da UNIABEU, 2017; 8(2): 104-114.

14. OLIVEIRA RR, ABREU MFAA. Construção de modelos como metodologia alternativa: uma reflexão sobre seu desenvolvimento. São Paulo: APADEC, 2013; 51p.

15. ROCHA HM, LEMOS WM. Metodologias ativas: do que estamos falando? Base conceitual e relato de pesquisa em andamento. São Paulo: IX Simpósio Pedagógico e Pesquisas em Comunicação, 2014. Disponível em: https://chpenhanews.wordpress.com/2014/07/30/ix- simposio-pedagogico-simped-3/. Acesso em: 1 jul 2020.

16. ROMAN C, et al. Metodologias ativas de ensino-aprendizagem no processo de ensino em saúde no brasil: uma revisão narrativa. Clinical \& Biomedical Research, 2017; 37(4): 349-357.

17. SANTOS AMG, et al. Desenvolvimento de metodologias ativas para o ensino de anatomia humana. Brazilian Journal of Development, 2019; 5(4): 3341-3352.

18. SENA S, et al. Aprendizagem baseada em jogos digitais: a contribuição dos jogos epistêmicos na geração de novos conhecimentos. Revista Novas Tecnologias na Educação, 2016; 14(1): 1-11.

19. SILVA RA, GUIMARÃES MM. Arte educação: facilitando o ensino de morfologia. São Paulo: Revista da Educação da UNIPAR, 2018; 8p. 